Animal maintained under anesthesia until 3 p. m. when, after another test was taken, it was allowed to recover.

3 p. m.: Blood withdrawn, cholesterin value, 0.358 .

EXPERIMENT 77.-April 1, 1916, male mongrel; animal very quiet; weight $15.1 \mathrm{~kg}$.

8 a. m.: Animal was given $1 / 9$ grain morphin and $1 / 100$ grain atropin subcutaneously.

$8: 30$ a. m.: Count of white blood cells was taken.

$8: 45$ a. m.: Etherized quickly by Cone method. Animal maintained under surgical anesthesia until $4 \mathrm{p}$. m., when it was allowed to recover.

The counts of white blood cells were as follows:

$$
\begin{array}{r}
\text { 8:30 a. m., } 18,050 \\
10: 00 \text { a. m., } 18,450 \\
11: 00 \text { a. m., } 20,000 \\
12: 00 \text { m. } 24,800 \\
\text { 1:00 p. m., } 28,650 \\
\text { 2:00 p. m., } 30,500 \\
\text { 4:00 p. m., } 35,800
\end{array}
$$

Experiment 89.-May 3, 1916, adult mongrel, male; weight $9 \mathrm{~kg}$.

$8: 15$ a. m.: Count of white blood cells taken from right ear vein and smears for differential count. Right jugular vein exposed under local anesthesia. Doubly ligated vein leaving it almost filled with blood. Length of vein, $8 \mathrm{~cm}$. Total white cells, 15,100. Differential count: polymorphonuclears, 76; large lymphocytes, 10; small lymphocytes, 5; transitionals, 4 ; eosinophils, 5.

$8: 30$ a. m.: Injected 1 c.c. suspension of Bacillus coli into vein. Vein markedly distended. Gently mixed by compression.

9 a. m.: Animal etherized.

9:30 a. m.: Smears taken from right jugular vein showed that 45.5 per cent. of the phagocytes contained bacteria and 54.5 per cent. did not contain bacteria.

11:30 a. m.: Took count of white blood cells from right ear vein; count 30,500 .

2:25 p. m.: Took count of white blood cells and smears for differential count from abdominal vein. Total count of white cells from abdominal vein, 47,430. Differential count: polymorphonuclears, 93 ; large lymphocytes, 3 ; small lymphocytes, 1 ; transitionals, 2 ; eosinophils, 1.

2:30 p. m.: Exposed and ligated left jugular vein. Injected 1 c.c. of same suspension of Bacillus coli. Technic same as used on right vein.

3 p. m.: Count of white blood cells from mesenteric vein, 46,650 .

$3: 30$ p. m.: Smears made from blood of left jugular vein showed that 57.5 per cent. of the phagocytes contained bacteria and 42.5 per cent. did not.

EXPERIMENT 91.-May 11, 1916, young male, mongrel; had had distemper for about four days; weight $8.5 \mathrm{~kg}$.

$8: 20$ a. m.: Exposed left jugular vein.

8:44 a. m.: White blood cells, 21,000.

$8: 45$ a. m.: Injected suspension Bacillus coli into ligated vein.

9 a. m.: Animal under ether.

9:45 a. m.: Made smears from left vein. Of the phagocytes 90 per cent. contained bacteria.

Animal maintained under surgical anesthesia.

3 p. m.: Exposed right jugular vein and injected bacteria.

$3: 02$ p. m.: Count of white blood cells, 40,100.

4 p. m.: Made smear from right vein. Ninety per cent. of the phagocytes contained bacteria.

Speech Following Explosions.-After explosions it has been found that in some of the survivors speech is affected. In some instances speech is entirely lost, and only comes back after many days. In others there is great difficulty in forming the words, and as the patient's mind generally is slow and confused, there is a curious impression given to the observer of great effort in the attempts to speak. The patient often repeats himself, iterating and reiterating words or phrases. This affection of speech may and generally does iast only for a few days, but in rarer cases it may be months before specch returns to normal.-Glaister.

\section{NITROUS OXID-OXYGEN ANESTHESIA IN MAJOR SURGERY *}

\author{
A. B. COOKE, A.M., M.D. \\ LOS ANGELES
}

To avoid misunderstanding, let me state at the outset that this paper is written from the point of view of the operator, not the anesthetist. No claim is made to special knowledge concerning the theory and technic of general anesthesia or the abstract merits of the several anesthetic agents, and no academic discussion along these lines will be attempted. My sole purpose is to present conclusions based on personal experience in operating under nitrous oxid-oxygen anesthesia, and to indicate some of the practical advantages it has seemed to afford in the field of major surgery.

It is fair to say at this point that no opinion as to the comparative value of anesthetics and methods of anesthesia is entitled to weight unless it is founded on the actual clinical experience of a competent and strictly impartial observer. Mere impressions are apt to be misleading; conjecture with reference to any scientific problem is always worse than useless. Desire to know the truth is the first essential. This established, the conditions of the investigation are quite certain to be safeguarded, and the final verdict to be a just one.

During the past three years I have performed approximately 300 major operations under nitrous oxid-oxygen anesthesia. Without stopping to enumerate them in detail, I may say that the list includes thyroidectomy, prostatectomy, the several procedures requiring preliminary dilatation of the sphincter ani, and excision of the rectum, as well as the various operations on the abdominal and pelvic viscera. In the great majority of these cases (certainly not less than 90 per cent.) not a drop of any other general anesthetic was used, though in practically all cases I employed local anesthesia in addition. I approve and advocate the addition of ether when it is indicated, in amount sufficient to secure the result desired; but from clinical observation I am of the opinion that, where this is necessary, it is because of some fault in the preparation of the patient, or, more rarely, due to some extraordinary complication of the operation itself. In such cases the amount of ether required is usually very small, not exceeding 1 or 2 drams as a rule, and a second occasion for its use rarely arises in the same operation.

In this connection it should be emphasized that local anesthesia is a most valuable adjunct to the successful employment of gas anesthesia. This is particularly true in abdominal cases in which muscular relaxation must be had to avoid undue traumatism. Here the result desired is readily accomplished by carefully infiltrating the nerve-bearing tissue of the abdominal wall with a weak solution of novocain $(1: 400)$ or cocain $(1: 1,000)$. The degree of relaxation secured is a true index to the thoroughness of the local infiltration.

The operative time in the 300 cases referred to varied from thirty minutes to two hours, averaging probably about one hour. I have not found it necessary in any case to suspend the work because the anesthetic was not well borne. In fact, as my confidence

* Read before the Section on Surgery, General and Abdominal, at the Sixty-Seventh Annulal Session of the American Medical Association,
Detroit, June, 1916 . 
in the gas-oxygen method and in my anesthetist has increased, I have come to look with less and less anxiety on cases that heretofore seemed most formidable, and to find myself willing to offer the aid of surgery to patients whom I should formerly have advised against operation.

In the entire series there was no fatality in any way chargeable to the anesthetic. Further, there was not an instance in which danger from this source even threatened a patient. Dr. R. F. Hastreiter, who has administered the gas most often for me, tells me that he has now administered it for surgical anesthesia more than 500 times without a fatality and without unfavorable symptoms in a single case.

\section{DISADVANTAGES}

There are certain inherent difficulties and disadvantages in the use of nitrous oxid. The first and most important of these is the difficulty of finding anesthetists skilled in its administration. The prevalent idea that anybody, including student and nurse, can give the anesthetic emphatically does not apply to this agent. On the contrary, rare judgment and much experience are required for its safe and successful cmployment. Happily this difficulty is not insuperable, since competent men are taking up the work in every community as the demand for gas anesthesia increases.

Another disadvantage is the more or less cumbersome character of the apparatus required. The ingenuity of the manufacturers has done much to overcome this difficulty, simplified outfits, both hospital and portable, being now provided which, if given proper care, are quite satisfactory. Where one is so fortunate as to be able to concentrate all his work in a single perfectly equipped hospital, this disadvantage is readily eliminated.

A third disadvantage is the relatively high cost of the gas. This has been greatly reduced by the improved methods of manufacture and handling, and to an equal or greater extent by improved methods of administration. Strictly speaking, the matter of cost does not enter into the question. The real consideration concerns only the best interests of the patient.

One other difficulty should be mentioned, namely, that of securing nitrous oxid entirely free from inpurities. When nitrous oxid first came into use as a general anesthetic, it was thought that a certain amount of cyanosis was necessary and inevitable in every case. We now understand that this condition is to be regarded as a danger signal, due for the most part to poisonous impurities in the gas, though it is, of course, true that the same effect may be produced by the unskilled anesthetist with gas of the purest quality. The valuable paper of Warner, ${ }^{1}$ describing the experience of Lakeside Hospital, clearly establishes the facts that it is perfectly practicable to produce pure gas, and that with the impurities the dangers of this agent as an anesthetic virtually disappear. His observation that entire freedom from cyanosis may be maintained, while the patient is otherwise presenting symptoms of asphyxia, is deserving of special note.

\section{LIMITATIONS}

The applicability of nitrous oxid as an anesthetic embraces the entire field of surgery, so far as my experience goes, wth a single exception. It is not satisfactory in major operations on the mouth, nose

1. Warner, A. R.: Manufacture and Administration of Nitrous Oxid fo: Ancethesia, Tile Journal A. M. A., Dec. 4, 1915, p. 1973. and air passages. To maintain surgical anesthesia with this agent requires the complete exclusion of atmospheric air, and the effect is so evanescent that the mask cannot be removed even momentarily without the patient's arousing. Breathing tubes have been devised to overcome this difficulty, but with only partial success. In such cases the anesthesia may be induced by the gas and ether substituted before the operation proper is begun, the patient thus escaping the primary stage of irritation and excitement. With this exception I know of no limitations in the practical application of this method of anesthesia.

\section{ADVANTAGES}

The advantages of nitrous oxid are numerous and may well be considered under two heads: first, those which concern the patient, and second, those which concern more particularly the operator and the hospital.

The two most important considerations from the standpoint of the patient are, of course, safety and comfort. Given a pure gas and a competent anesthetist, I am fully convinced that nitrous oxid is at least equally as safe as ether and, when the possibility of postoperative complications attributable to the anesthetic is included, more so. No one will gainsay that no such marked depression is observed following the former as the latter. In explanation of this fact we have only to remember that ether lowers the blood pressure while nitrous oxid raises it ; that free perspiration and the consequent dissipation of the body heat is the rule under ether, while such a phenomenon is rarely observed under nitrous oxid; that the effects of ether are persistent, lasting usually for twenty-four hours or longer, while the effects of nitrous oxid are by comparison decidedly transient. We further know that ether is one of the best of all lipoid solvents and that, being so diffusible, it permeates practically every fat-bearing tissue of the body, necessitating increased elimination at a time when the patient's organs are least able to respond. Postoperative pneumonia and suppression of urine following ether anesthesia are by no means rare. It will probably never be definitely known just how often the lighting up of a latent tuberculous process or the inception of an ultimately fatal nephritis may be due to the same cause.

Many factors contribute to the comfort of the patient under nitrous oxid-oxygen anesthesia. Any fair-minded observer who will study and contrast the condition of the patient before, during and after the operation in two similar cases, or series of cases, in which gas and ether respectively are administered by equally competent anesthetists, cannot fail to be impressed with the comparative merits of the former in this regard. The disagreeable effects of ether anesthesia are common knowledge, and inspire no small part of the dread with which surgery is contemplated. With the proper assurance in advance, the patient approaches nitrous oxid anesthesia in a much more tranquil frame of mind - unquestionably a distinct gain. Nitrous oxid is nonodorous, nonirritating, and produces unconsciousness with the first few inhalations. No sensation of strangling, no talking or struggling, no nausea result. When the flow of gas is stopped, full consciousness is regained in a very few moments, and nausea and vomiting are chiefly notable for their rarity of occurrence. In the exceptional case in which emesis is seen, it is more in the nature of a simple regurgitation, usually occurs only once, and is 
not accompanied by the deathly nausea and depression which result so commonly from ether. With respect to the several bodily functions, the normal is regained with striking rapidity. This is a matter of hours, not days, and convalescence from the operation, not from the operation plus the anesthesia, is much more promptly established, of shorter duration, and more comfortable in every way.

The gentleness of manipulation required, in operating under nitrous oxid, I regard as one of its most pronounced advantages. The anesthesia produced by this agent is never so deep and deathlike as that of ether. To operate successfully under nitrous oxid demands a studied respect for all tissues at every stage. By this means unnecessary traumatism is avoided, the amount of postoperative wound repair lessened, and the vitality of the patient conserved. The surgeon who regards the spectacular and his time record of supreme importance cannot hope to find this method of anesthesia entirely satisfactory.

I am convinced that nitrous oxid very appreciably broadens the field of surgery in that it makes it possible to extend its benefits to certain cases and conditions in which the administration of ether would involve too great danger. It is no small thing to be able to assure a weakened and suffering patient that he may have the chance of relief to which he is entitled without assuming undue risk from the anesthetic itself. Several times within my own experience, patients have been successfully operated on when, with ether as the dependence, I should have approached the cases with the utmost reluctance and apprehension, if, indeed, I could have persuaded myself to undertake them at all.

From the standpoint of the operator and the hospital there are several additional advantages in nitrous oxid anesthesia which, while of secondary importance, to be sure, are yet worthy of being mentioned. There is a considerable saving of time in the operating room because of the rapidity with which the gas acts and because, when the operation is over, the patient, conscious and quiet, may be returned to his bed without the usual delay. The few minutes thus saved in handling a single case might easily swell into an hour or more in the course of a busy day - an item of no little moment both to surgeon and operating-room force.

A further very decided advantage to the hospital develops in the postoperative care of gas patients. The time of every hospital employee has a definite money value. After ether anesthesia the more or less constant attention of a nurse is usually required for a period varying from a few hours to twenty-four hours or more, depending on the amount of depression and the persistence of nausea and vomiting. This costs money. The use of gas does away with the need for so-called recovery rooms, the patient, conscious and comfortable, being returned directly to his own bed in a ward or room. Thus the disturbance of other inmates is minimized and the natural apprehension of other patients approaching the ordeal of operation allayed, instead of increased.

\section{CONCLUSION}

There is no topic before the profession today commanding greater interest than that of anesthesia, and rightly so, for it is universally recognized that further progress in surgery is dependent in no small degree on advances along this line.
The ideal anesthetic for major surgery is the one capable of producing analgesia and unconsciousness without danger or discomfort to the patient. Any agent or method which furthers this ideal - which tends in any way to relieve surgery of its harshness, and to smooth down the rough places on a road to health that patients justly regard as both formidable and forbidding, should receive our most earnest and open-minded attention. My experience with nitrous oxid as an anesthetic would seem to warrant the conclusion that it is entitled to high rank in this beneficent class.

508 Hollingsworth Building.

\section{ABSTRACT OF DISCUSSION}

Dr. W. I. Terry, San Francisco: I am in full accord with Dr. Cooke's conclusions as to the use of nitrous oxid and oxygen in major surgery. I have used this method consistently for the past four years in about 1,200 major cases and $I$ am convinced that from the standpoint of the patient himself it is the best and safest anesthetic we have, when supplemented by local anesthesia. The absence of odor, the rapidity of action, the minimized after-effects are all for the comfort of the patient. The absence of heart, kidney, liver, blood and lung conditions postoperatively are the factors of safety which do not apply to the same degree with other general anesthetics. It seems to me that there are two principal reasons why the method has not had a very extended use. First, the lack of thoroughly trained anesthetists, and second, the increased cost. Both these factors will prevail against it until they can be modified and ether will still remain the method of choice where nitrous oxid and oxygen are not obtainable under the right conditions. Another objection that has frequently been made is the lack of muscular relaxation, particularly in abdominal work. This, to me, is simply a matter of technic in the use of the local anesthetic. When the local anesthetic is employed properly muscular relaxation is obtained, provided always that the nitrous oxid is given properly and the patient is kept in the right condition. With alcoholics, however, and some athletes, it is often necessary to give a little ether in addition, but in a minimum amount. The total is very small, indeed, in these cases. Another objection is that more time must be taken to do these operations, but time should not be measured against safety.

Dr. Charles K. Teter, Cleveland: Nitrous oxid oxygen in general surgery has been in practically constant use in at least two Cleveland hospitals for over ten years. Cleveland was, I think, the first city where a nitrous oxid plant for the manufacture of nitrous oxid was installed in a hospital. The plant was installed first in St. Luke's Hospital about nine years ago and a little over one year afterward another plant was established in Lakeside Hospital. These plants, with modifications, have been in use ever since. Constant use of nitrous oxid in major surgery has proved to us that this anesthetic has its limitations, and I do not think that we have been led so far in our enthusiasm as to claim that it is the anesthetic of choice in every case. In most cases of minor surgery nitrous oxid and oxygen will give sufficient depth of anesthesia so as not to interfere with the accomplishment of the operation. The physical properties of nitrous oxid are such that it must be given at least 80 to 95 per cent. pure in order to bring about surgical anesthesia. No oxygen is liberated during its sojourn in the organism. Therefore it is an asphyxiant as well as an anesthetic, so that when you withhold less than the normal amount of oxygen in atmospheric air you have a certain degree of interference with normal oxidation, and if you give as high as 20 per cent. of oxygen you will not. have surgical aresthesia, as we understand it. You will have perfect unconsciousness but not relaxation of the musculature. Then it becomes necessary to add something to nitrous oxid. Our method is to use preanesthetic narcotics, as morphin, $1 / 8$ to $1 / 4$ grain, atropin, $1 / 150$ to $1 / 100$ grain; 
then if relaxation cannot be had, a sufficient amount of ether vapor is added to the mixture. Some object and say, "If you must add ether what is the use of giving nitrous oxid at all?" I claim that if you can withhold even 2 ounces of ether in a major operation you have done a great favor to that patient. In most of the apparatus on the market you will find ether attachments and some of you have prob: ably noticed that there is a considerable amount of ether used during an hour's anesthesia. For instance, there may be 4 ounces of ether taken up in the gas as it passes through it, but you must remember that the 4 ounces of ether does not all go to the patient. There is a considerable volume of the gas escaping through the exhalation valve and a lot of this ether is wasted.

\section{STAB WOUNDS OF THE CHEST INVOLV- ING THE DIAPHRAGM}

WITH DIAPHRAGMATIC HERNIA OR EVISCERATION *

\section{CHARLES C. GREEN, M.D.}

HOUSTON, TEXAS

Although man has inhabited this world nearly 8,000 years and has possessed a temper since the time of Cain and Abel, and has had in his possession a knife or some kindred instrument, with which he has inflicted wounds in almost every portion of the human anatomy, yet not until recently have there appeared in literature any reports of stab wounds of the diaphragm, with diaphragmatic hernia, or evisceration.

The question then naturally arises, Is there an increase of this character of injuries, or are we becoming better diagnosticians and now recognize them, where they were previously overlooked?

The latter is the more logical conclusion, as there has been no change in the anatomy of man, and little or none in the character of cutlery used by him in settling his personal difficulties.

The term "hernia," as applied in these cases, is a misnomer, since hernia always has a sac, which in these cases is lacking. Consequently the term "evisceration," which is used entirely by the French writers, is the more correct.

Diaphragmatic hernia and evisceration are found on the right side in 8 per cent., and on the left side in 92 per cent. of all cases. The small percentage of cases fourd on the right side is due to the fact that the liver is situated on this side, and acts as a plug for almost any opening that may be made in this locality.

Quite recently, a great deal has been written on this subject, and the most comprehensive articles have been contributed by Wolf, Iselin, Suter and Magoula.

Magoula's article was published in 1910, and includes all cases previously reported by Wolf, Iselin and Suter, with some additional cases. Therefore, I invite attention to a brief review of this paper.

Magoula reviewed the whole subject of stab wounds of the chest in 1910, and reported 190 cases of injury to the diaphragm ; but by no means did all of these have hernias.

Of the sixty-four cases reported by Suter, fortyfour cases showed protrusion at the outer wound; five showed protrusion of the omentum into the pleura; ten showed only slight protrusion through the diaphragm, and five showed the stomach herniated tinrough the diaphragm.

* Read before the Section on Surgery, General and Abdominal, at the Sixty-Seventh Annual Session of the American Medical Association, Detroit, June, 1916 .
Of the thirteen cases reported by Wolf, five showed hernia.

Of sixty-one personal cases reported by Magoula, nine showed the omentum at the outer wound, and four showed protrusion through the diaphragm.

Of forty other cases collected by Magoula, twelve showed the omentum at the outer wound, and four showed the viscera through the diaphragm.

Hence, of the 190 cases reported by Magoula, ninetyeight, or nearly 52 per cent., showed hernia, or better, evisceration.

From this brief review it is seen that the total number of cases of wounds of the chest, involving the diaphragm, with a hernia, is ninety-eight, plus twentyfive others that have been reported since the publication of Magoula's paper, as follows: Bamberger, Frassi, Caffee, Gautierand Du Seutre, Fato, Gourevitch, Gougorlof, Klaggs and Krymholz, each one; McGuire, Negroni and Wiess, each two; Jobes three, and Davis seven, making a grand total of 123 cases which have been reported.

To this number I wish to add six cases which I treated at St. Joseph's Infirmary, Houston, Texas.

\section{REPORT OF CASES}

CASE 1.-Man, aged 28, white, married, was admitted to the hospital with a stab wound of the left chest just posterior to the midaxillary line, through which about 6 inches of omentum were protruding, at the ninth interspace. The wound was inflicted by his wife with a carving knife. He was immediately given $1 / 2$ grain of morphin and $1 / 150$ grain of atropin. He was taken to the operating room, and under anesthesia a median incision was made. A careful examination of the cavity showed that there were two incisions in the omentum, and a small incision in the stomach through all coats except the mucous membrane. The bleeding points were caught and ligated, and the incision in the stomach was closed with a fine catgut suture.

Further examination of the cavity disclosed the fact that there was an opening in the diaphragm, through which some of the viscera had escaped into the thoracic cavity. With one hand in the cavity I succeeded in replacing them, but they were immediately sucked back into the thorax, with a great deal of force and an audible, sucking sound. The abdomen was then closed, as we found it next to impossible to conclude the operation through this opening. We then enlarged the wound of entrance, excised a portion of the rib, and, on inspection, found that all of the transverse colon, and omentum, a portion of the descending colon and jejunum and stomach were in the thoracic cavity. After some disiculty, they were replaced into the abdominal cavity, and the edges of the rent in the diaphragm were caught up with forceps and sutured with No. 3 chromic catgut, and the outer wound was closed without drainage.

The patient was then taken to the ward and made an uneventful recovery. He left the hospital in twelve days, and today is in perfect health.

CAse 2.-Man, aged 32, white, married, was brought into the hospital with a stab wound of the left chest in the midaxillary line, at the seventh interspace, with 4 inches of omentum protruding. He was suffering from profound shock, but reacted nicely after the administration of $1 / 2$ grain of morphin and $1 / 150$ grain of atropin. $\mathrm{He}$ was then taken to the operating room and under ether anesthesia, a median incision was made. A portion of omentum, and stomach was found in the thoracic cavity with a large rent in it, from which there was profuse hemorrhage. This point was picked up and ligated, and, no other injury being found, the abdomen was closed in the usual way. The wound of entrance was then enlarged, as in the first case, but we did not find it necessary to resect the rib. The stomach and omentum were returned into the abdominal cavity, the opening was closed as in Case 1, and the patient was sent to the 